\title{
Child Abuse in India
}

\author{
Dr. Mohammad Reza Iravani \\ Assistant Professor \\ Payam Noor University (PNU), Esfahan, Iran \\ Tel: 98-913-194-3910Ｅ-mail: Irani2010@gmail.com
}

\begin{abstract}
Child abuse is harm to, or neglect of, a child by another person, whether adult or child. Child abuse happens in all cultural, ethnic, and income groups. Child abuse can be physical, emotional - verbal, sexual or through neglect. Abuse may cause serious injury to the child and may even result in death.

A problem that is only beginning to come into light in India rape, sexual abuse, and sexual harassment are worldwide issues of gender violence. There is very little research done in this area in India and only a few books have been written, keeping the subject even further from the consciousness of the country. However, the problem persists with staggering incidence, and Indians unique profile adds to the complexity of an already difficult subject. Fortunately, the issue of child sexual abuse is slowly becoming a more recognized issue, and for this reason, this paper will focus much on sexual abuse against minor children: the laws, victims, and perpetrators. Finally, an analysis of the aspects of Indian culture that make this issue particularly difficult to understand and cope with will be presented.
\end{abstract}

Keywords: Social problems, Child welfare, Victimized, Poverty, Verbal abuse

\section{Introduction}

The Indian subcontinent, in fact, still has many groups, such as the Baiga, where actual incestuous marriage is practiced, between fathers and daughters, between mothers and sons, between siblings and even between grandparents and their grandchildren--thus disproving the oft-repeated anthropological truism that "no known tribe has ever permitted incest" because if it were allowed society would surely cease functioning. In many of these villages, the children move at the age of 5 or 6 from the incestuous activities of the family bed to spend the rest of their childhood in sex dormitories, where they are initiated by older youth and men into intercourse with a succession of other children, none for longer than three days at a time, under threat of gang rape.

In India the most accurate scientific studies, based on lengthy interviews, report that 30 percent of men and 40 percent of women remember having been sexually molested during childhood-defining "molestation" as actual genital contact, not just exposure. About half of these are directly incestuous, with the family members, the other half usually being with others, but with the complicity of caretakers in at least 80 percent of the cases. These experiences of seduction are not just pieced together from fragmentary memories, but are remembered in detail, are usually for an extended period of time and have been confirmed by follow-up reliability studies in 83 percent of the cases, so they are unlikely to have been fantasies. The seductions occurred at much earlier ages than had been previously assumed, with 81 percent occurring before puberty and an astonishing 42 percent under age 7 . As high as these molestation rates seem, however, they represent only a portion of the true rates, not only because those interviewed do not include populations that have been shown to have extremely high rates, such as criminals, prostitutes, juveniles in shelters, psychotics, etc.--but also because only conscious memories were counted, and the earliest seductions of children are almost never remembered except during psychotherapy. Adjusting statistically for what is known about these additional factors, I have concluded that the real sexual abuse rate for America is 60 percent for girls and 45 percent for boys, about half of these directly incestuous.

No matter what anxieties one had, one had children always at hand to use to relieve them. The evolution of childhood from incest to love and from abuse to empathy has been a slow, uneven path, but one whose progressive direction is, I think, unmistakable. This evolution of parent-child relations is, I contend, an independent source of historical change, lying in the ability of successive generations of parents to live through their own childhood traumas a second time and work through their anxieties in a slightly better manner this second time around. It is in this sense that I say that history is like psychotherapy, which also heals through revisiting one's childhood traumas and reworking earlier anxieties. If the parent--the mother, for most of history--is given even the most minimal support by society, the evolution of childhood progresses, new variations in historical personality are formed, and history begins to move in new, innovative directions. 


\section{Sexual Abuse}

Child tells you he/she was sexually mistreated. Child has physical signs such as:

Difficulty in walking or sitting. Stained or bloody underwear. Genital or rectal pain, itching, swelling, redness, or discharge bruises or other injuries in the genital or rectal area.

The sexual use of children in the Near East is as widespread as in the Far East. Historically, all the institutionalized forms of pedophilia which were customary in the Far East are documented extensively for the Near East, including child marriage, child concubine, temple prostitution of both boys and girls, parent-child marriage (among the Zoroastrians), sibling marriage (quite common among Egyptians), sex slavery, ritualized pederasty and child prostitution. Masturbation in infancy is said to be necessary "to increase the size" of the penis, and older siblings are reported to play with the genitals of babies for hours at a time. Mutual masturbation, fellatio and anal intercourse are also said to be common among children, particularly with the older boys using younger children as sex objects. The nude public baths (hammam) are particularly eroticized in many areas, being especially notorious as a place of homosexual acts, both male and female.

It is more unfortunate to say that it is evident that all above mentioned kinds of abuses exists among child labourers. A number of explanations have been given by social scientists to reveal the major motivational factors behind the child abuse. Psychiatric and Socio Cultural Explanation. Social cultural explanation includes a) social-situational b) social habitability and c) social control explanations. Recently social scientists have added 3 more types of explanations. 1 resource explanation, 2 social interact ional and 3 social learning explanations.

\section{Socio-cultural}

Explanation says those external forces or a socio-demographic variable within the society causes child abuse. This theory has 3 major sub fields 1 social situational, 2 social habitability and 3 social controls. The social-situational explanation proposes that abuse and violence arise out of two factors: structural stress and cultural norms. As the social structure in which a parent lives becomes more stress ridden greater becomes the possibility that family violence will surface as an attempt to gain control over irritating, tense events. Cultural sanctioning of violence as an appropriate conflict resolution technique further provides a foundation for the use of corporal punishment in child rearing. If a parent was frequently exposed to harsh physical punishment as a child, he/she may have great propensity toward viewing such behavior as normative and inhibition against physical force may be lessened (Bendura, 1973).

Psychiatric explanations the psychiatric explanation was propounded by many scholars. It links with child abuse factors such as mental illness and personality defects or intra-individual abnormalities. It also links abusive parents' own childhood experiences to the individuals' weak personality development and poor self-control. The thesis that personality disorder is responsible for child abuse was further advanced by reports that abusers often had a propensity for impulsive and/or antisocial acts that extended beyond the preventing role. A parent, according to this explanation, may abuse his/her child due to unmet emotional needs and capabilities with own (parental) expectations, or emotional scars from their own abusive or deprived family background affecting their ability to care for their own offspring (Bhasak, 1998). This explanation initially drew support from many support from many fields, including law-makes and public-interest groups because it directed most of the responsibility for abusive behavior squarely at the individual involved, and absolved society from blame in contributing to the risk of child abuse through lack of education, adequate housing, family support programmers, employment opportunities, and so on. However, recent researches have disproved the role of psychopathology in child abuse (Burgess, 1989).

Research regarding the causes of child abuse has recently undergone a paradigm shift. The results of research initiated by the National Research Council's Panel on Research on Child Abuse and Neglect ${ }^{8}$ signal the first important step away from simple cause-and-effect models. As was recognized by researchers for the National Research Council's panel, the simple cause-and-effect models have certain limitations, mainly related to their narrow focus on the parents. These models limit themselves by asking only about the isolated set of personal characteristics that might cause parents to abuse or neglect their children. Moreover, these models also fail to account for the occurrence of different forms of abuse in one child. At the same time, these models had very little explanatory power in weighing the value of various risk factors involved in child abuse. As a result, they were not very accurate in predicting future cases of child abuse.

To replace the old static model, the panel has substituted what it calls an "ecologic" model. This model considers the origin of all forms of child abuse to be a complex interactive process. This ecologic model views child abuse within a system of risk and protective factors interacting across four levels: (1) the individual, (2) the family, (3) the community and (4) the society. ${ }^{8,15,16}$ However, some factors are more closely linked with some forms of abuse than others. ${ }^{8}$ The factors thought to contribute to the development of physical and emotional abuse and neglect of children are listed in Table 2 and are discussed below. 
In Social control view some parents use violence against their children because they have no fear of being hit back. Social interact ional explanation approach the etiology of child abuse in terms of the interplay between individual family and social factors in relation to both past and present events. The condition in which children have been raised may help to reveal why some adults are predisposed to abusive behavior, given certain setting conditions. Social learning theory lays emphasis on the learned nature of parenting and the fact that many parents have lack of knowledge and skill to carry out the highly complex task of child-rearing. (Kumar, 2003)

In India, the demand for children comes mainly from the local population. However, India and other South Asian countries are gradually replacing South East Asia as the venue of choice for foreigners, as there are fewer laws against child sexual abuse, and South Asian children can be bought at more affordable prices. The Convention on Rights of the Child has been rectified and supported by 178 countries including India. It given the NGOs, lawyers, government officials, and Policy officers, no choice except to take all possible measures in ensuring protection of the rights of children. We do not need more legislation's. We already have a number of laws, which are not being implemented.

\section{Neglect}

Child abuse and neglect can be defined as the intentional, non accidental injury, malnutrient of children by parents, caretaker, employers or others including those individuals presenting Government/non Government bodies which may lead to temporary or permanent impairment of their physical, mental, psycho-social development, disability of death (Uma, 1990). Children, particularly infants, are perhaps the most vulnerable victims of crime, because of their very great dependence upon their parents. Its is a tragic fact that children suffer to a fall greater extent as the hands of parents and their friends then they do as the hands of strangers. This type of abuse can be further classified in to physical neglect, emotional neglect, moral neglect and social neglect.

\section{Emotional abuse}

Child emotional abuse can be refereed to as a pattern of behavioral that impairs a child emotional development or sense of self worth. This may include constant criticism, threats or rejection as well as withholding love, support, or guidance. Emotional maltreatment is rarely manifested in physical signs. A few physical indicators of emotional maltreatment are speech disorders, lag in physical development and failure-to-thrive syndrome. The behavioral characteristics of emotional maltreatment are habit disorders, conduct disorders neurotic trait psycho-neurotic reaction behavior extremes (passive, aggressive, rigid reserved, demanding stubborn), and lag in emotional and intellectual, and attempted suicide. Four important causes emotional abuse are poverty, deficient parental control and non cordial relations within family, maltreatment faced by parents in their child hood or inter generational transmission of child mal treatment, and alcoholism of parents. A significant proportion of abusing parents were themselves abused as children (National Clearinghouse Information, 2004).

\section{Emotional - Verbal Abuse}

Aggressive or withdrawn behavior. Shying away from physical contact with parents or adults. Afraid to go home.

\section{Physical abuse}

Unexplained or repeated injuries such as welts, bruises, or burns. Injuries that are in the shape of an object (belt buckle, electric cord, etc.) Injuries not likely to happen given the age or ability of the child. For example, broken bones in a child too young to walk or climb. Disagreement between the child's and the parent's explanation of the injury. Unreasonable explanation of the injury. Obvious neglect of the child, (dirty, undernourished, inappropriate clothes for the weather, lack of medical or dental care).

It can be defined a situation in which a child suffers, or is likely to suffer, significant harm from an injury inflicted by the child's parent or caretaker. It is more visible form of abuse among working children than children who normally resides with the parents. If a child failed in executes the order of his boss the boss may get angry and beat, burn, fracture, abrasion etc. Boys are more batten than girls. Also school going children well be more beaten by the other children. The studies have revealed that mothers abuse children physically more than of the fathers. Also this study further says expressive violence is one in which the use of physical is an end in itself. Instrumental or power oriented violence is one in which violence is intended not only as a menace of including the child to alter his behavior but also to establish parental authority. Child precipitated violence is one in which the victims of violence contribute to their own victimization either thorough action defined as deviant by the aggressor parent or through provoking their antagonism.

\section{Causes of physical abuse}

Many social scientists have given different causes of physical abuse. Some consider the psycho-pathology of the individual perpetrators as the primary causes factor, other view the psycho social pathology of family interaction 
as the main cause, and still others put major emphasis on situations of acute as tress. The situational stresses pointed out four models of dominant causes of a child's physical abuse 1 relation between couples 2 relations between parents and children 3 structural stress, and 4 child-produced stress. Totally we can say that through the role of the personality traits of the abusers cannot be ignored but family environment and stress radian family situations are more crucial in child battering.

The NGOs role has almost become a pattern of speech. The chosen rhetoric is that the NGOs are the closest to the target groups, that the NGO role is the critical and most important one. It is a way of transferring responsibility from one sector to another. The government and we, however, cannot shun the responsibility. NGOs can be partners, not substitutes, in the government's efforts. There is need to raise public sensitivity and awareness about these problems that confront us in our work. The problem of child prostitution has to be worked out not merely through rehabilitation, but with greater emphasis on prevention. There are backward villages and districts that provide the base for the traffickers. That is where the real problem. NGOs working towards rural development should focus on such poor families that are willy-nilly-forced to send their children to earn. We lack the skills to search the underworld Mafia that is dangerous. There are people who are making a loss of money in trafficking. We have witnessed the power of community action in Manila where the parents of the children came out on the street and demanded justice; and in Goa where protestation are going on; the beach areas of Sri Lanka, where small community groups are committed to monitor the problem in order to protect their own children. The community has to rise up and join hands, though it is not something that is going to be easy.

\section{Conclusion}

Although child abuse is a pervasive and complex problem with many causes, we should not take a defeatist attitude toward its prevention. Despite the absence of strong evidence to guide our preventive efforts, physicians can do many things to try to prevent abuse. At the very least, showing increased concern for the parents or caregivers and increasing our attempts to enhance their skills as parents or caregivers may help save our most vulnerable patients from the nightmare of abuse and neglect.

In sum, rape and sexual abuse of children in India is a large problem without an easy solution. Though the issue persists worldwide, India's culture which traditionally keeps women below men, makes talk of private matters such as such unallowable, and a corrupt and weak legal system when it comes to rape makes the problems even larger. However, the situation could be improved by appropriately educating children and adults on sexual abuse, and educating police and strengthening laws. Further women's empowerment may lead to healthy changes as well.

It is clear that we as physicians cannot hope to solve the problem of child abuse by ourselves. Many things need to happen at international, national, state and community levels to prevent child abuse. The physician who is concerned for the welfare of children should be an advocate for more accessible, affordable and high-quality child and health care in the local community. Studies have shown that countries with the most generous social services have the lowest rate of child homicide. ${ }^{16}$ Physicians should lobby for greater availability of drug and alcohol treatment programs, more shelters for the homeless, more accessible mental health care and more shelters for abused women and children. These programs and those that provide parenting skills, support groups and respite care for parents and caregivers should be available in every community.

\section{References}

Dubowitz H. (1990). Pediatricians' role in preventing child maltreatment. Pediatric Clin North Am, 37: 989-1002.

Lewit EM. (1994). Reported child abuse and neglect. Future Child, 4(2):233-42.

MacMillan HL, Macmillan JH, Offered DR, Griffith L, MacMillan A. (1994). Primary prevention of child physical abuse and neglect: a critical review. Part I. J Child Psycho Psychiatry, 35(5):835-56.

National Center for Health Statistics. Vital statistics of the United States. Vol. II. Mortality. Hyattsville, Md. (1996). Department of Health and Human Services, Public Health Service, Centers for Disease Control and Prevention.

Pitt SE, Bale EM. (1995). Neonaticide, infanticide, and filicide: a review of the literature. Bull Am Acad Psychiatry Law, 23(3):375-86.

Rushton FE. (1996). The role of health care in child abuse and neglect prevention. $J S C$ Med Assoc, 92(3):133-6.

Wissow LS. (1995). Child abuse and neglect. N Engel J Med, 332:1425-31. 